\title{
The correlation between methylenetetrahydrofolate reductase gene polymorphism and high-risk pregnancy:a retrospective cohort study
}

\author{
Jiahui Shen ${ }^{1}$, Yanhui Jiang ${ }^{1}$, Jie Liu ${ }^{1}$, Le Chen ${ }^{1}$, Yaochao Yang ${ }^{1}$, Xiaoe Zeng ${ }^{1}$, and Qiwen \\ Yuan $^{1}$ \\ ${ }^{1}$ Fifth Affiliated Hospital of Sun Yat-sen University
}

August 21, 2020

\begin{abstract}
Objective: To explore the correlation between methylenetetrahydrofolate reductase (MTHFR) 677C-T polymorphism and highrisk pregnancy(HRP), and to establish a useful HRP management model during the perinatal period. Design:Retrospective cohort study Setting:The Fifth Hospital of Sun Yat-sen University Population:All women gave birth in the obstetrics departmen between 2018 and 2020. Methods:Using polymerase chain reaction and restriction fragment length polymorphism analysis (PCRRFLP) method to detect MTHFR677C-T genotype. Screening is base on whether the maternal has diagnosis HRP and have a regular antenatal care. The correlation between HRP and MTHFR677C-T polymorphism explained by chi-square test and the logistic regression. Main Outcome Measure: The alleles and genotypes of MTHFR $677 \mathrm{C}-\mathrm{T}$ and the prevalence and classification of HRP. Results:A total of 2,372 were eventually enrolled, including 584 cases in the HRP group and 737 cases in the control group. The MTHFR 677C-T allele was in Hardy- Weinberg equilibrium(P>0.05). The MTHFR 677C-T polymorphism and allele $(\mathrm{T})$ were associated with HRP $(\mathrm{P}<0.05)$. To be specific, they associated with Hypertensive disorders of Pregnancy(HDP), Pregnancy with thyroid disease, gestational anemia and Preterm $\operatorname{birth}(\mathrm{PTB})(\mathrm{P}<0.05)$. After adjusting for confounders, the mutant genotype $(\mathrm{C} / \mathrm{T}+\mathrm{T} / \mathrm{T})$ remained a susceptibility factor for HDP and $\mathrm{PTB}(\mathrm{P}<0.05)$. The allele $(\mathrm{T})$ was associated with HDP, Gestational diabetes mellitus and $\mathrm{PTB}(\mathrm{P}<0.05)$. Conclusions:The MTHFR 677C-T polymorphism was associated with HRP, especially HDP and PTB. It is necessary to establish a useful model to manage the women during the perinatal period. Funding: None Keywords:high-risk pregnancy, MTHFR677C-T, pregnancy comorbidities. Tweetable abstract:MTHFR 677C-T polymorphism is associated with high-risk pregnancy.
\end{abstract}

\section{Hosted file}

Title page.doc available at https://authorea.com/users/352781/articles/476903-thecorrelation-between-methylenetetrahydrofolate-reductase-gene-polymorphism-and-high-riskpregnancy-a-retrospective-cohort-study

\section{Hosted file}

Manuscript.doc available at https://authorea.com/users/352781/articles/476903-thecorrelation-between-methylenetetrahydrofolate-reductase-gene-polymorphism-and-high-riskpregnancy-a-retrospective-cohort-study 